\title{
Response to: Comment on "Establishing a Porcine Model of Small for Size Syndrome following Liver Resection"
}

\author{
Mohammad Golriz $\left(\mathbb{D}\right.$, Elias Khajeh (D), Omid Ghamarnejad (D), and Arianeb Mehrabi $\mathbb{D}^{\circ}$ \\ Department of General, Visceral, and Transplantation Surgery, University of Heidelberg, Heidelberg, Germany \\ Correspondence should be addressed to Arianeb Mehrabi; arianeb.mehrabi@med.uni-heidelberg.de
}

Received 7 May 2018; Accepted 23 May 2018; Published 19 August 2018

Academic Editor: Pierluigi Toniutto

Copyright (c) 2018 Mohammad Golriz et al. This is an open access article distributed under the Creative Commons Attribution License, which permits unrestricted use, distribution, and reproduction in any medium, provided the original work is properly cited.

With great interest we read the most recent letter of Athanasiou et al. [1], this time about our publication [2]. The mentioned issues can be categorized in the following subjects:

Transhepatic Flow (THF) Variations and Small for Size and Flow Syndrome (SFSF). The important role of THF variations in SFSF has been clarified by our group previously [3]. However, the mechanism and definition of SFSF should not be confused with one another. Variations in THF cause SFSF and can be considered a prerequisite factor for SFSF [4], but THF variations are not necessary for confirmation of the diagnosis. Moreover, we have previously showed the THF variations following extended liver resection $[5,6]$. SFSF is diagnosed based on the clinical, laboratory, and, if possible, histopathological findings [7]. Hemodynamic variations during and after liver resection are measured to correlate these values with the diagnosis and to define prognostic cut-off values. Measuring hemodynamic variations could add extra information to our study but was not necessary to confirm the diagnosis.

Remnant Liver Volume (RLV) and SFSF. SFSF and posthepatectomy liver failure (PHLF) are often mistaken as the same, and this is shown in the comments made by Athanasiou. This mistake is common because SFSF and PHLF are usually overlapping [8]. However, SFSF is a clinical syndrome after liver resection which can lead to irreversible PHLF but can also be prevented from ending in that. SFSF causes PHLF because of small RLV and increased portal vein flow per 100 gr remnant liver. An optimal animal model of SFSF for evaluating the preventive, diagnostic, and therapeutic procedures has to mirror the deterioration in liver function and have the capacity to be compensated or reversed. In the clinical setting, no surgeon will resect that much liver to make PHLF and death inevitable $[9,10]$. In other words, an SFSF model should be reversible and may be rescued by intervention. However, most of the animals in SFSF model die from PHLF if no intervention is received. This can be reached in porcine model through a trisectionectomy [1115]. Moreover, the resection cut-off level depends on the size of segments 1, 6, and 7. If these segments are large, it is sometimes necessary to resect a further $5 \%$ to achieve the cutoff level $[16,17]$. Resection that causes early death without the possibility for potential compensation (irreversible) is not an optimal SFSF model. To establish and understand a proper animal model, enough experience with the anatomy and physiology of the animal is required, especially in the respective field [18-24].

Triggers of Liver Regeneration. Triggers of liver regeneration have to be differentiated from liver regeneration itself. It is true that hypoxia may trigger liver regeneration [25]. However, constant hypoxia causes liver failure. Hypertrophy after liver resection is not explained by hypoxia; it is triggered by hypoxia. Moreover, the arterial buffer response cannot be reversed $[26,27]$.

Summary. SFSF following extended liver resection is a complex process that is often mistaken with liver failure after partial liver transplantation or considered as equal to PHLF. 
However, SFSF is a clinical syndrome after liver resection which can lead to irreversible PHLF but can also be prevented from ending in that. In other word, every SFSF is a reversible PHLF which can end in irreversible PHLF.

\section{Conflicts of Interest}

The authors declare that they have no conflicts of interest.

\section{References}

[1] A. Athanasiou, E. Spartalis, M. Hennessy, M. Spartalis, and E. Pikoulis, "Comment on "establishing a porcine model of small for size syndrome following liver resection", Canadian Journal of Gastroenterology and Hepatology, vol. 2018, Article ID 4915817, 2 pages, 2018.

[2] M. Golriz, M. Ashrafi, E. Khajeh, A. Majlesara, C. Flechtenmacher, and A. Mehrabi, "Establishing a porcine model of small for size syndrome following liver resection," Canadian Journal of Gastroenterology and Hepatology, vol. 2017, Article ID 5127178, 8 pages, 2017.

[3] M. Golriz, A. Majlesara, S. El Sakka et al., "Small for Size and Flow (SFSF) syndrome: An alternative description for posthepatectomy liver failure," Clinics and Research in Hepatology and Gastroenterology, vol. 40, no. 3, pp. 267-275, 2015.

[4] J. M. Asencio, J. Vaquero, L. Olmedilla, and J. L. García Sabrido, "'Small-for-flow" syndrome: Shifting the "size" paradigm," Medical Hypotheses, vol. 80, no. 5, pp. 573-577, 2013.

[5] M. Golriz, S. El Sakka, A. Majlesara et al., "Hepatic Hemodynamic Changes Following Stepwise Liver Resection," Journal of Gastrointestinal Surgery, vol. 20, no. 3, pp. 1-8, 2015.

[6] M. Golriz, A. Majlesara, E. Khajeh, and A. Mehrabi, "Reply: Hepatic Hemodynamic Changes Following Stepwise Liver Resection (Golriz et al. J Gastrointest Surg (2016) 20: 587-594)," Journal of Gastrointestinal Surgery, vol. 20, no. 12, pp. 2109-2110, 2016.

[7] A. J. Demetris, D. M. Kelly, B. Eghtesad et al., "Pathophysiologic observations and histopathologic recognition of the portal hyperperfusion or small-for-size syndrome," The American Journal of Surgical Pathology, vol. 30, no. 8, pp. 986-993, 2006.

[8] K. Lafaro, S. Buettner, H. Maqsood et al., "Defining post hepatectomy liver insufficiency: where do we stand?" Journal of Gastrointestinal Surgery, vol. 19, no. 11, pp. 2079-2092, 2015.

[9] A. Guglielmi, A. Ruzzenente, S. Conci, A. Valdegamberi, and C. Iacono, "How much remnant is enough in liver resection?" Digestive Surgery, vol. 29, no. 1, pp. 6-17, 2012.

[10] C. Yigitler, O. Farges, R. Kianmanesh, J.-M. Regimbeau, E. K. Abdalla, and J. Belghiti, "The small remnant liver after major liver resection: How common and how relevant?" Liver Transplantation, vol. 9, no. 9, pp. S18-S25, 2003.

[11] R. Ladurner, B. Hochleitner, S. Schneeberger et al., "Extended liver resection and hepatic ischemia in pigs: A new, potentially reversible model to induce acute liver failure and study artificial liver support systems," European Surgical Research, vol. 37, no. 6, pp. 365-369, 2005.

[12] F. G. Court, P. E. Laws, C. P. Morrison et al., "Subtotal hepatectomy: A porcine model for the study of liver regeneration," Journal of Surgical Research, vol. 116, no. 1, pp. 181-186, 2004.

[13] T. Iida, S. Yagi, K. Taniguchi, T. Hori, and S. Uemoto, "Improvement of Morphological Changes after 70\% Hepatectomy with
Portocaval Shunt: Preclinical Study in Porcine Model," Journal of Surgical Research, vol. 143, no. 2, pp. 238-246, 2007.

[14] H. Wege, A. Müller, L. Müller, S. Petri, J. Petersen, and C. Hillert, "Regeneration in pig livers by compensatory hyperplasia induces high levels of telomerase activity," Comparative Hepatology, vol. 6, no. 1, p. 6, 2007.

[15] R. Ladurner, M. Schenk, R. Margreiter, F. Offner, and A. Königsrainer, "Influence of portosystemic shunt on liver regeneration after hepatic resection in pigs," HPB Surgery, vol. 2009, p. 835965, 2009.

[16] S. M. Niehues, J. K. Unger, M. Malinowski, J. Neymeyer, B. Hamm, and M. Stockmann, "Liver volume measurement: reason of the difference between in vivo CT-volumetry and intraoperative ex vivo determination and how to cope it," European Journal of Medical Research, vol. 15, no. 8, pp. 345350, 2010.

[17] F. G. Court, S. A. Wemyss-Holden, C. P. Morrison et al., "Segmental nature of the porcine liver and its potential as a model for experimental partial hepatectomy," British Journal of Surgery, vol. 90, no. 4, pp. 440-444, 2003.

[18] M. Golriz, S. Abbasi, P. Fathi, A. Majlesara, T. Brenner, and A. Mehrabi, "Does acid-base equilibrium correlate with remnant liver volume during stepwise liver resection?" American Journal of Physiology-Gastrointestinal and Liver Physiology, vol. 313, pp. G313-g319, 2017.

[19] A. Groth, S. Ottinger, C. Kleist et al., "Evaluation of porcine mesenchymal stem cells for therapeutic use in human liver cancer," International Journal of Oncology, vol. 40, no. 2, pp. 391401, 2012.

[20] G. Millonig, S. Friedrich, S. Adolf et al., "Liver stiffness is directly influenced by central venous pressure," Journal of Hepatology, vol. 52, no. 2, pp. 206-210, 2010.

[21] M. Soleimani, H. Fonouni, M. Esmaeilzadeh et al., "Appropriate donor size for porcine liver xenotransplant," Experimental and Clinical Transplantation, vol. 10, no. 2, pp. 148-153, 2012.

[22] M. Esmaeilzadeh, A. Nickkholgh, A. Majlesara et al., "Technical guidelines for porcine liver allo-transplantation: A review of literature," Annals of Transplantation, vol. 17, no. 2, pp. 101-110, 2012.

[23] T. Gehrig, G. Manzini, H. Fonouni et al., "Comparison of two different transection techniques in liver surgery - An experimental study in a porcine model," Langenbeck's Archives of Surgery, vol. 398, no. 6, pp. 909-915, 2013.

[24] M. Golriz, M. Hafezi, C. Garoussi et al., "Do we need animal hands-on courses for transplantation surgery?" Clinical Transplantation, vol. 27, supplement 25, pp. 6-15, 2013.

[25] E. Schadde, C. Tsatsaris, M. Swiderska-Syn et al., "Hypoxia of the growing liver accelerates regeneration," Surgery, vol. 161, no. 3, pp. 666-679, 2017.

[26] H. Ho, K. Sorrell, A. Bartlett, and P. Hunter, "Modeling the hepatic arterial buffer response in the liver," Medical Engineering \& Physics, vol. 35, no. 8, pp. 1053-1058, 2013.

[27] C. Eipel, K. Abshagen, and B. Vollmar, "Regulation of hepatic blood flow: the hepatic arterial buffer response revisited," World Journal of Gastroenterology, vol. 16, no. 48, pp. 6046-6057, 2010. 


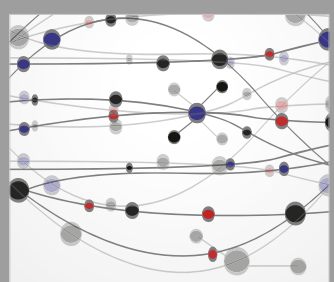

The Scientific World Journal
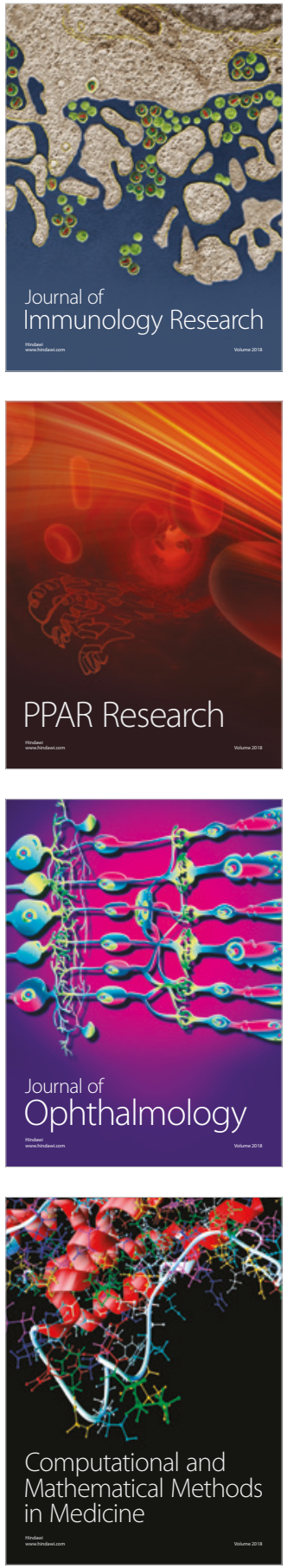

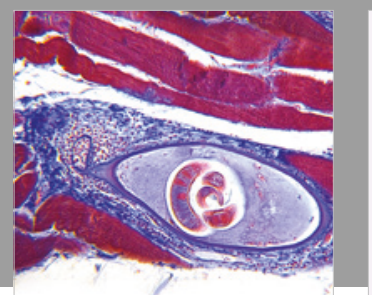

Gastroenterology Research and Practice

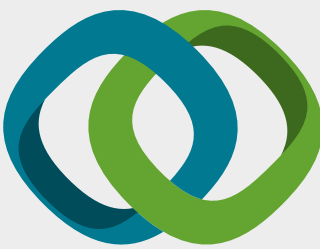

\section{Hindawi}

Submit your manuscripts at

www.hindawi.com
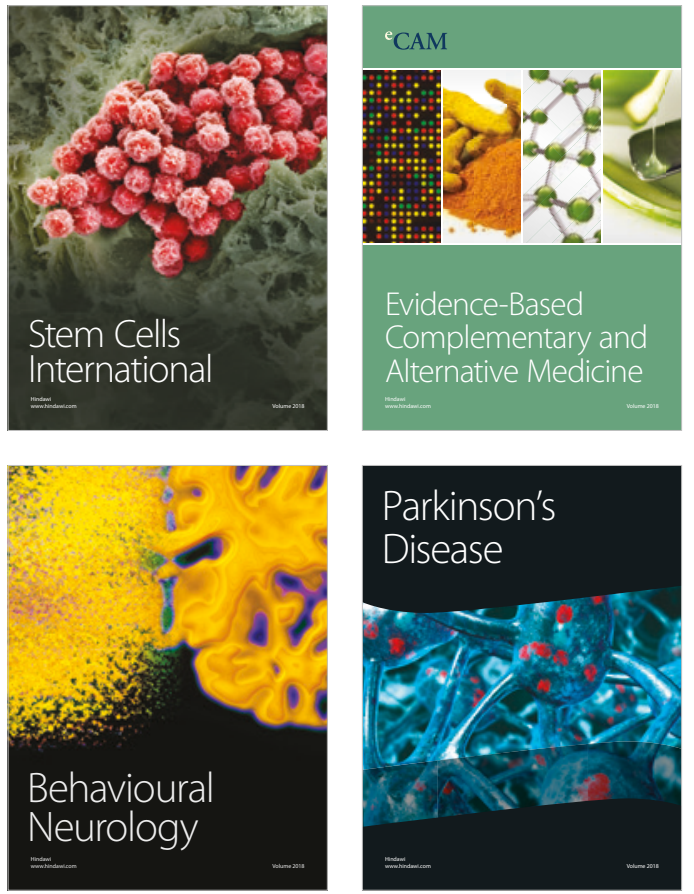

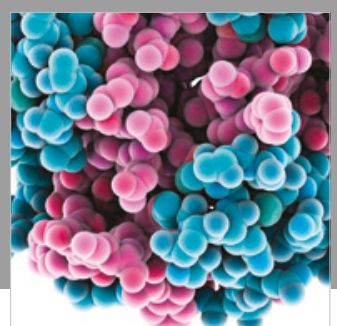

ournal of

Diabetes Research

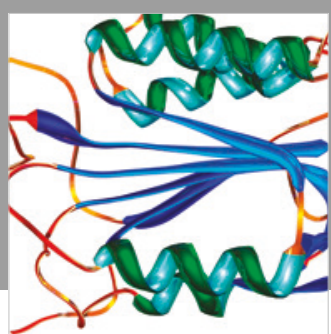

Disease Markers
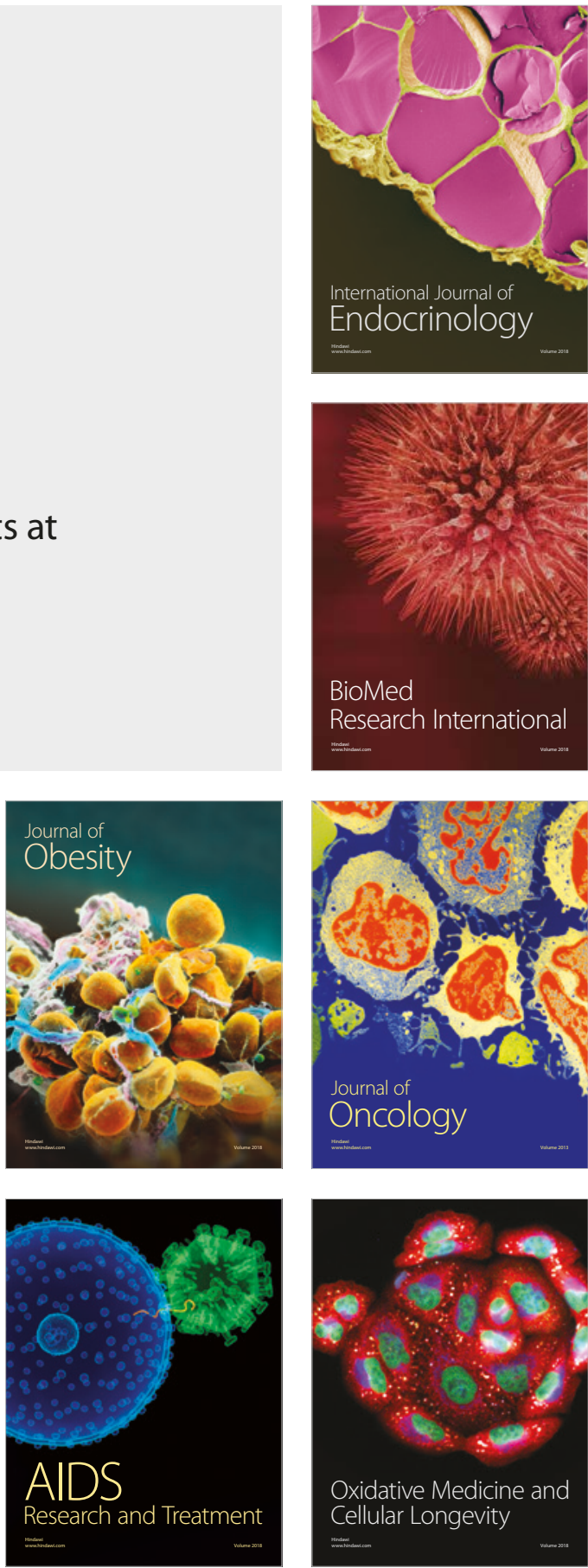